\title{
The Puzzle of Income, Race, and Density: \\ Preliminary Evidence on Transit Use from the 1991 American Housing Survey
}

\author{
Sandra Rosenbloom \\ Kelly Clifton \\ The Drachman Institute, The University of Arizona
}

\begin{abstract}
The article presents the results of a preliminary analysis of transit ridership data from the 1991 American Housing Survey. The findings suggest that transit operators may find new markets in places they had not thought to look: among high income travelers, including high income minority travelers.
\end{abstract}

\section{Introduction}

The importance of public transit in the travel patterns of many Americans has decreased sharply in the last two decades; today, no more than 1 in 20 American workers commutes via transit. In response to declining or threatened ridership many public transit operators have attempted to either 1) find or create new markets, or 2) strengthen and expand ridership among their current markets. Unfortunately, transit operators may not fully understand the nature of transit use among current riders or the potential market niches among other groups in society. 
The Drachman Institute of the University of Arizona, under contract to the Transit Cooperative Research Program of the National Research Council, has been investigating the nature of existing and emerging transit markets in the United States. This paper reports on the initial phase of that research, focusing on the role of income, race and ethnicity, and density in transit usage patterns.

A preliminary assessment of the 1991 American Housing Survey (AHS) suggests that these factors do not always work in the ways we have traditionally assumed. Low income is not always related to greater transit use, nor high income to lower transit use. Moreover, blacks and Hispanics are more likely to use transit at all income levels than comparable white workers. Finally, the size of a metropolitan area is more predictive of higher transit use than is its density. All these findings suggest that transit operators will have to 1) more carefully target services to various groups and, 2) re-think the kind of services which they offer various markets.

The first section below compares 1991 AHS transit patterns to those seen in other national data and in earlier AHS. Subsequent sections focus on traditional ways to segment those who generally commute by transit and evaluations of the impact of community density (people/sq. mile) on transit use among specific market groups.

\section{The Data Source}

\section{Basic Details}

The AHS provides extensive information on housing at the national and metropolitan statistical area (MSA) level; it also allows researchers to disaggregate market niches for the home-to-work trip, seeing who the current riders of transit really are. Conducted by the Bureau of the Census in odd-numbered years, roughly 50,000 housing units are surveyed; however, transportation data are collected only as a supplement to housing data and only for the commute trip. Because the focus of analysis is the housing unit rather than the household or its members, the uses to which the transportation data should be put are limited. While the survey attempts to sample a wide variety of types of housing units; 
there is no effort to ensure a comprehensive sample of people by race, sex, income, etc.

The Census Bureau provides weighting coefficients for the data, which allows data users to create a national sample - by housing type-but not by the characteristics of the people living in those houses. Because the 1991 data are not weighted by demographic variables, AHS data cannot be normalized to represent a national survey of transit users. However, as long as there are sufficient responses in specific demographic categories, the AHS can describe transit use by different kinds of people-so we can question, for example, what percentage of women or blacks or people making over $\$ 60,000$ generally take some form of public transit to go to work.

The transportation data in the AHS do suffer from other problems in addition to not being collected specifically for transportation purposes: 1) respondents are asked to recall their most frequent modes (rather than writing down each trip and mode) and 2) they are asked to state their most common work trip mode even if they use more than one. As a result, a) people can forget some of the trips which they made and b) people who take transit one or two days per week are not counted as transit users.

\section{National Comparisons}

Table 1 compares 1991 AHS data both to previous AHS and to two major 1990 surveys - the Census and the Nationwide Personal Transportation Survey (NPTS). The 1991 AHS data appear to be reasonably close to those collected from other sources for time and distance on the work trip commute; there are more differences on transit usage. Overall, the AHS has traditionally shown a slightly lower rate of transit ridership for the home to work commute than other sources; the 1990 Nationwide Personal Transportation Survey reports 5.5 percent of workers using transit compared to 4.32 percent of 1991 AHS respondents.

The AHS, however, is consistent with the other data sets in depicting a continual decline in transit use. From 1985 to 1989, when the percentage of workers using transit dropped to roughly 4.5 percent, the number of work trips actually increased more than 12 percent; thus the real drop in market share was more than 
4 percent between 1985-89.' As Table 1 shows, from 1989 to 1991 transit use for the work trip dropped still further-to 4.32 percent.

Data from the 1990 Census show the same trends; both the number and percentage of workers using transit to commute to work has dropped substantially since 1980. In 1990, 5.12 percent of workers used a public transit modecompared to 6.22 percent in $1980 .{ }^{2}$ This was an almost 18 percent drop in the actual number of workers commuting via transit even as the total number of workers increased almost 20 percent between 1980 and $1990 .{ }^{3}$ Public transit use was slightly higher in metropolitan areas over one million-9 percent in 1990 - but the number and percentage of public transit commuters was also falling in these larger areas.

The NPTS data also show steadily declining transit usage: in 1990, 5.5 percent of home to work trips were made using public transit; the comparable percentage was 8.1 percent in $1969 .{ }^{4}$ Some analysts feel that the surveying tech-

\section{Table 1}

Comparing AHS Data to Other Recent Transportation Surveys

\begin{tabular}{ccccc} 
& AHS & & $\begin{array}{c}\text { U.S. } \\
\text { Census }\end{array}$ & NPTS \\
\hline $1985^{\prime}$ & $1989^{\prime}$ & 1991 & $1990^{2}$ & $1990^{3}$
\end{tabular}

Transit Use

for Work Trip

$\begin{array}{lllll}5.10 \% & 4.50 \% & 4.32 \% & 5.12 \% & 5.50 \%\end{array}$

Average Length

$10.80 \mathrm{mi} \quad--$

$11.99 \mathrm{mi}$

$10.60 \mathrm{mi}$

(All Modes)

Average Time of Work Trip

$20.90 \mathrm{~min} \quad--$

$20.81 \mathrm{~min}$

$22.40 \mathrm{~min}$

$19.70 \mathrm{~min}$

(All Modes)

'Alan E. Pisarski, Travel Behavior Issues in the 90's, U.S. Department of Transportation, Federal Highway Administration, July 1992: 19.

${ }^{2}$ U.S. Department of Transportation, Federal Highway Administration, Journey-to-Work Trends in the U.S. and Its Major Metropolitan Areas 1960-1990, FHWA-PL-(\$-012), November 1993: 2-2. ${ }^{3}$ Patricia S. Hu and Jennifer Young, Summary of Travel Trends: 1990 NPTS, U.S. Federal Highway Administration, March 1992: 22. 


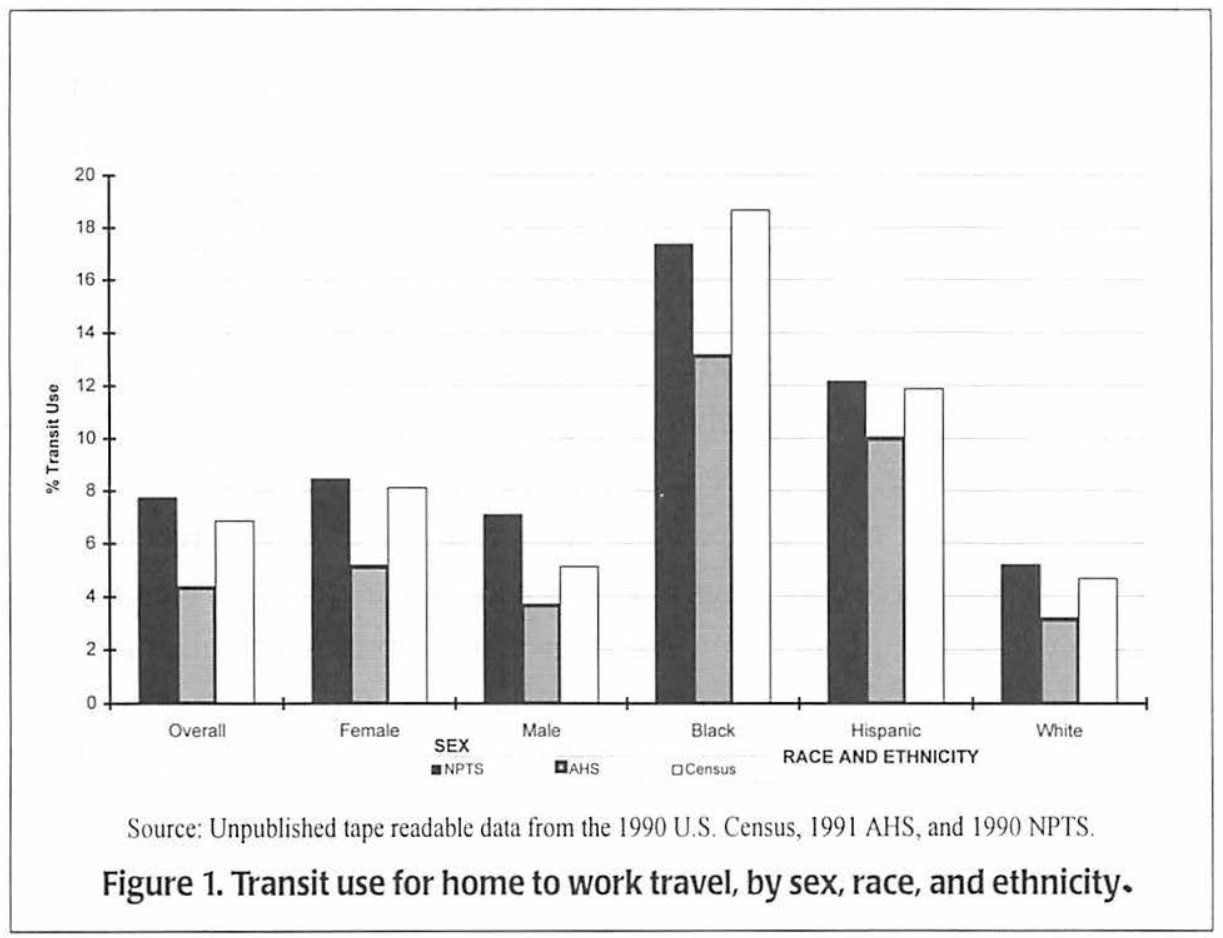

niques used by the NPTS have lead to a substantial undercounting of all transit trips ${ }^{5}$ - some contend as much as 20 percent..$^{6}$ If true, the fact that AHS data show even lower transit usage may suggest that the approach used to generate an appropriate sample of housing units in some way leads to an even greater undercounting of transit use.

The 1991 AHS also indicates that groups long dependent on public transit are still disproportionately more likely to commute by transit: for example, women and minorities. Figure 1 shows that more than 5 percent of all women but only 3.65 percent of men were transit commuters. At the same time Hispanics (of any race), blacks, and Asians were substantially more likely to use public transit for their work trips than whites. For example, over 13 percent of blacks and 10 percent of Hispanics (of any race) used transit to go to work - compared to just over 3 percent of whites. 


\section{The Role of Income in Transit Use}

Analysts generally believe that income is an important predictor of transit use; much of the reliance of women and minorities on public transit is assumed to be the result of the generally lower income of these large groups. However, the AHS data show that the relationship between traditional indicators-income, race, sex-and transit ridership is more complex than traditionally thought.

First, Figure 2 shows that-in contrast to general expectations-people with very low incomes were less likely to use public transit than those with higher incomes. For example, only 3.5 percent of those with incomes under $\$ 5,000$ used transit for their work trip-compared to 5.6 percent of those with incomes between $\$ 5-10,000$. Table 2 suggests a reason: people with very low incomes are more likely to work at home. However, transit still captures a smaller share of very low income people who actually leave their home to work than of those making more money-roughly 3.82 percent (compared to 4.76 percent of those making $\$ 10-15,000$, for example).

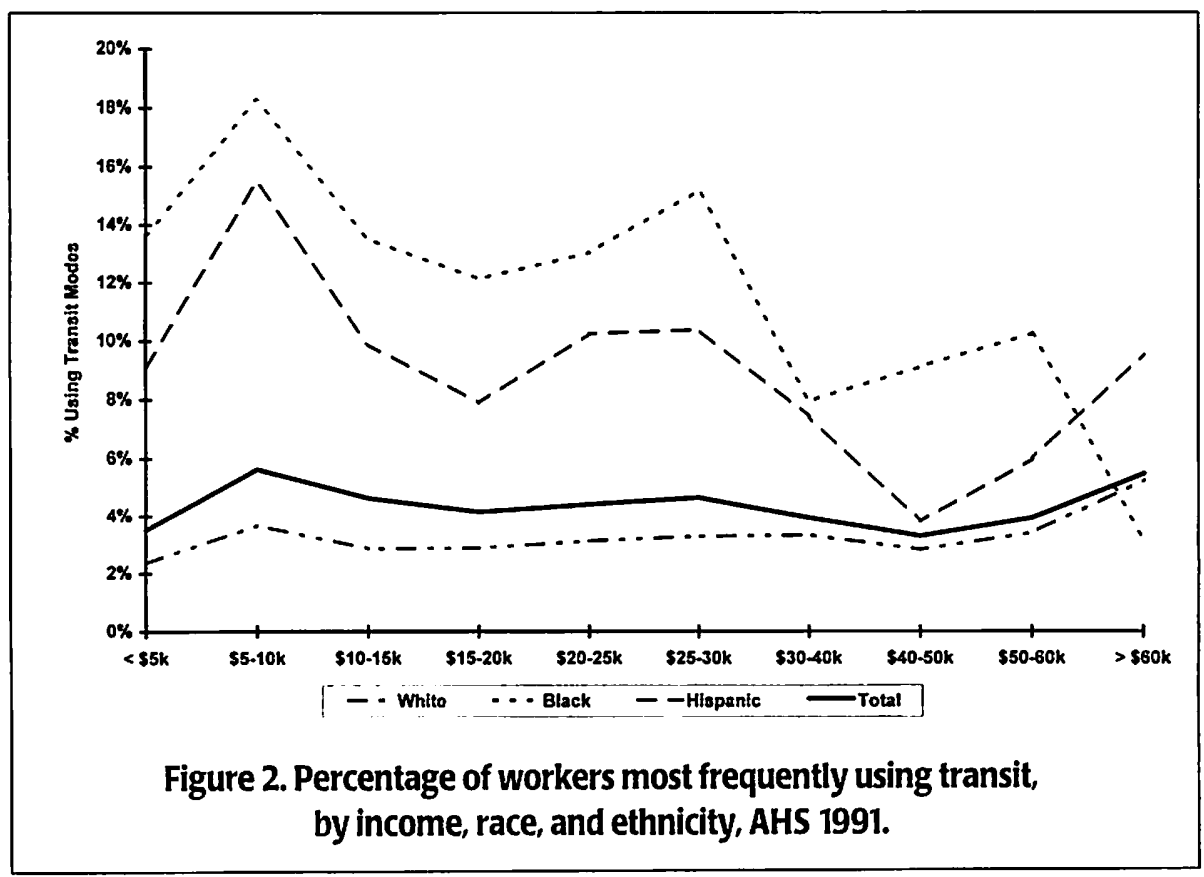


Second, as traditionally assumed, the propensity to use public transit does generally decline as income increases-but not nearly as directly as thought. To begin, overall transit use did not drop as rapidly as income increased; for example, the same percentage of workers with incomes between $\$ 10-15,000$ and between $\$ 25-30,000-4.6$ percent—used transit to commute to work. Just as importantly, transit usage went up as income went above $\$ 40,000$, so that people making between $\$ 10-15,000$ and those making more than $\$ 60,000$ had the same propensity to commute via transit.

Third, Figure 2 shows sometimes remarkable differences between those from different ethnic and racial backgrounds. At all income levels, blacks and Hispanics (of any race) were substantially more likely to use transit than whites or than the average. At the same time, transit usage was relatively stable among whites from incomes of $\$ 5-50,000$ so that the same percentage of whites making $\$ 20,000$ and making $\$ 50,000$ used transit to work.

There are some traditional explanations for these findings; transit use by high income travelers may be related to the use of heavy and commuter rail in the cities that account for so large a percentage of total transit ridership-New York, Chicago, Philadelphia, Boston, and Washington. As Figure 3 shows, the relationship between traveler income and transit use does vary among the transit modes. While bus use drops sharply with income, subway and commuter rail use increases fairly consistently with income-roughly 1 percent of workers

\begin{tabular}{|lcccc|}
\hline \multicolumn{5}{|c|}{$\begin{array}{l}\text { Table 2 } \\
\text { Principal Home-to-Work Mode of Selected } \\
\text { Income Groups, 1991 AHS }\end{array}$} \\
& \multicolumn{4}{c|}{ Household Income Levels (in 000) } \\
\cline { 2 - 5 } & $>\$ 5$ & $\$ 5-10$ & $\$ 10-15$ & $\$ 30-40$ \\
All Transit & $3.50 \%$ & $5.64 \%$ & $4.63 \%$ & $3.95 \%$ \\
$\quad$ Walked Only & 5.75 & 5.07 & 3.71 & 1.81 \\
$\quad$ Works at Home & 8.47 & 2.88 & 1.92 & 1.19 \\
$\quad$ Bike & 0.80 & 0.66 & 0.59 & 0.29 \\
$\quad$ Motorcycle & 0.13 & 0.18 & 0.17 & 0.24 \\
All Low Cost Efforts & 15.15 & 8.79 & 6.39 & 3.53 \\
Car/Truck/Van & 80.73 & 85.07 & 88.69 & 92.00 \\
\hline
\end{tabular}


with incomes between $\$ 10-15,000$ and almost 2 percent of workers with incomes between $\$ 40-50,000$ used the subways or elevated systems to go to work. In fact, rail as well as subway/elevated use was highest among workers with incomes above $\$ 60,000$; more than 2 percent of all workers with incomes between $\$ 60$ 70,000 used commuter rail (compared to 0.23 percent of all travelers).

However, while increasing rail and subway use among high income people explains the angle of the upward curve, it doesn't explain the magnitude. In fact, the 1991 AHS data show that bus use also increases at higher incomes. For example, 4.11 percent of those earning more than $\$ 60,00$ use bus-roughly the same percentage as those earning between $\$ 30-40,000$.

A traditional explanation for the bus use patterns is that, since most transit riders live in larger, denser communities where there are better transit options, they are more likely to use the bus even at higher incomes. Since blacks and Hispanics are also more likely to be concentrated in larger, denser cities, their higher dependence on transit in aggregate national figures may just be an artifact

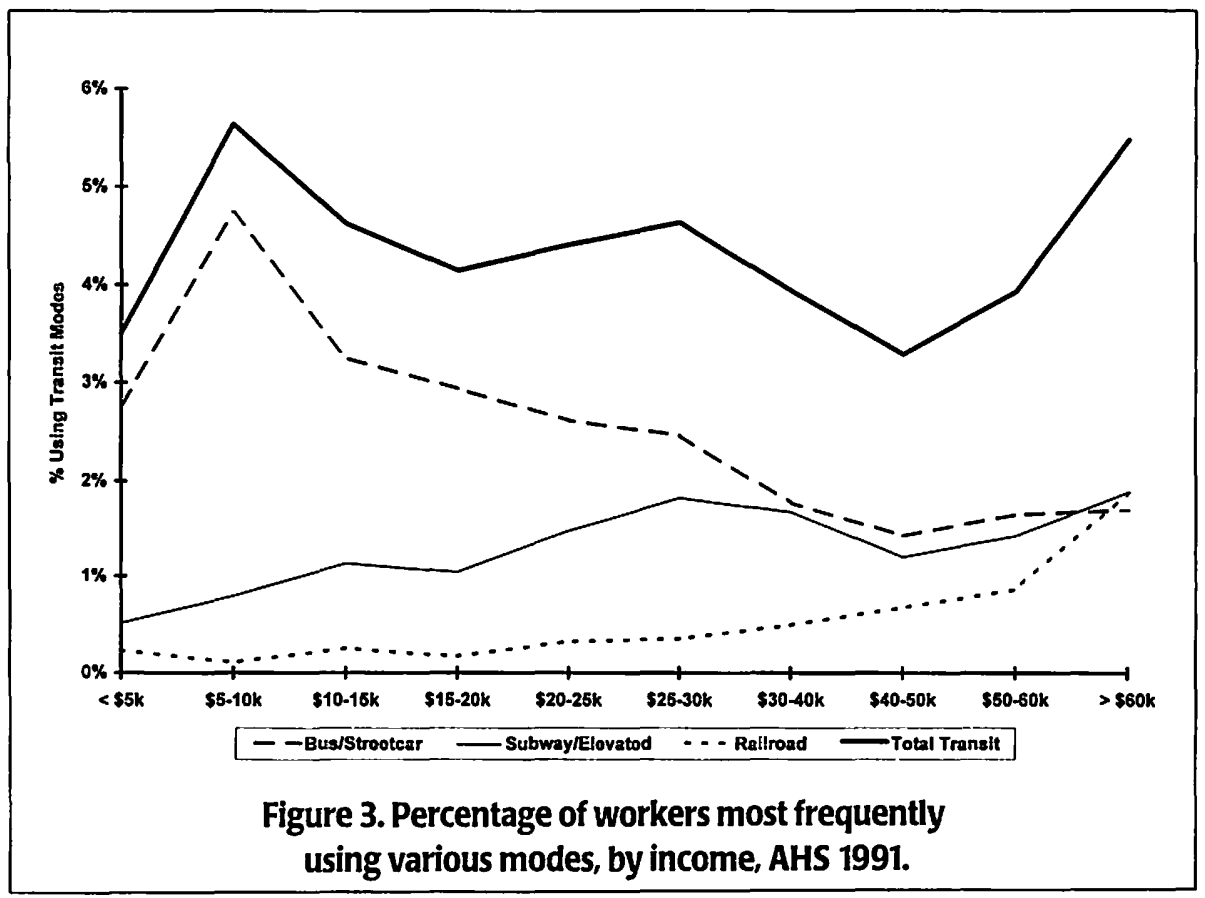


of where they live. In short, one possibility is that transit use does not generally increase with incomes over $\$ 40,000$, nor that blacks are more likely to use transit at all incomes, but rather that more blacks and Hispanics and people making those incomes live in New York or Chicago or Boston, etc, where transit use is inherently higher. If so, 1) most high income transit use would disappear in smaller metropolitan areas, and, 2) people of color would not be more likely than other workers with comparable incomes to use either bus or rail transit-within specific individual metropolitan areas, even high density ones.

To assess this explanation, the AHS data were divided into 14 metropolitan categories, characterized by both size and density. The density data were taken from the 1990 Census (Summary Tape File 3-STF3) as people/sq.km which were converted to people/sq. miles, and imported into the AHS data set. We used four sizes of metropolitan area:

- under 200,000

- 200-500,000

- 500,000 to one million

- over one million

We also used four categories of density: very low-under 50 people per square mile, low-50-1,000 people per sq. mile; medium $-1,000-2,000$ people per sq. mile; and high-over 2,000 people per mile. In addition, New York and Chicago were broken out separately; ultimately there were 14 categories since cities did not exist in each of the 16 potential size/density categories. In addition, the very low density categories fell out of the analysis because they lacked transit services. Obviously, using such large categories, and categorizing as high density those cities with only 2,000 people per sq. mile, may introduce some large biases, as does the use of average density data to represent an entire city.

In order to assess whether high income transit ridership in aggregate U.S. data was explained by rail use in large cities, Figure 4 evaluates bus ridership as well as rail use in high density metropolitan areas. It is clear, as predicted, that larger denser cities had much higher relative bus mode splits-which tended to decrease with increasing income. In all high density metropolitan areas over one million, bus use - while relatively higher than in smaller cities—plummeted as 
income increased. However, in an unexpected outcome, bus use suddenly began to increase at incomes above $\$ 60,000$. In short, while higher rail use in large cities explains some of the higher income transit use seen in aggregate national figures, it does not explain it all.

Figure 5 helps us analyze the second part of the question: does higher bus use in larger, denser cities explain higher income transit use in aggregate U.S. figures? If it did, we would not expect to see higher incomes groups taking the bus to work in smaller or less dense cities; Figure 5 focuses on bus use by income in three smaller service environments. While the trend is not entirely "clean," it appears that bus use first falls steadily with increasing income-but then begins to rise again at incomes above $\$ 40,000$. For example, in medium density metropolitan areas between one-half and one million, a higher percentage of those making more than $\$ 60,000$ used a bus than those making $\$ 20-25,000$. In low density areas of the same size, those making $\$ 50-60,000$ used the bus to work

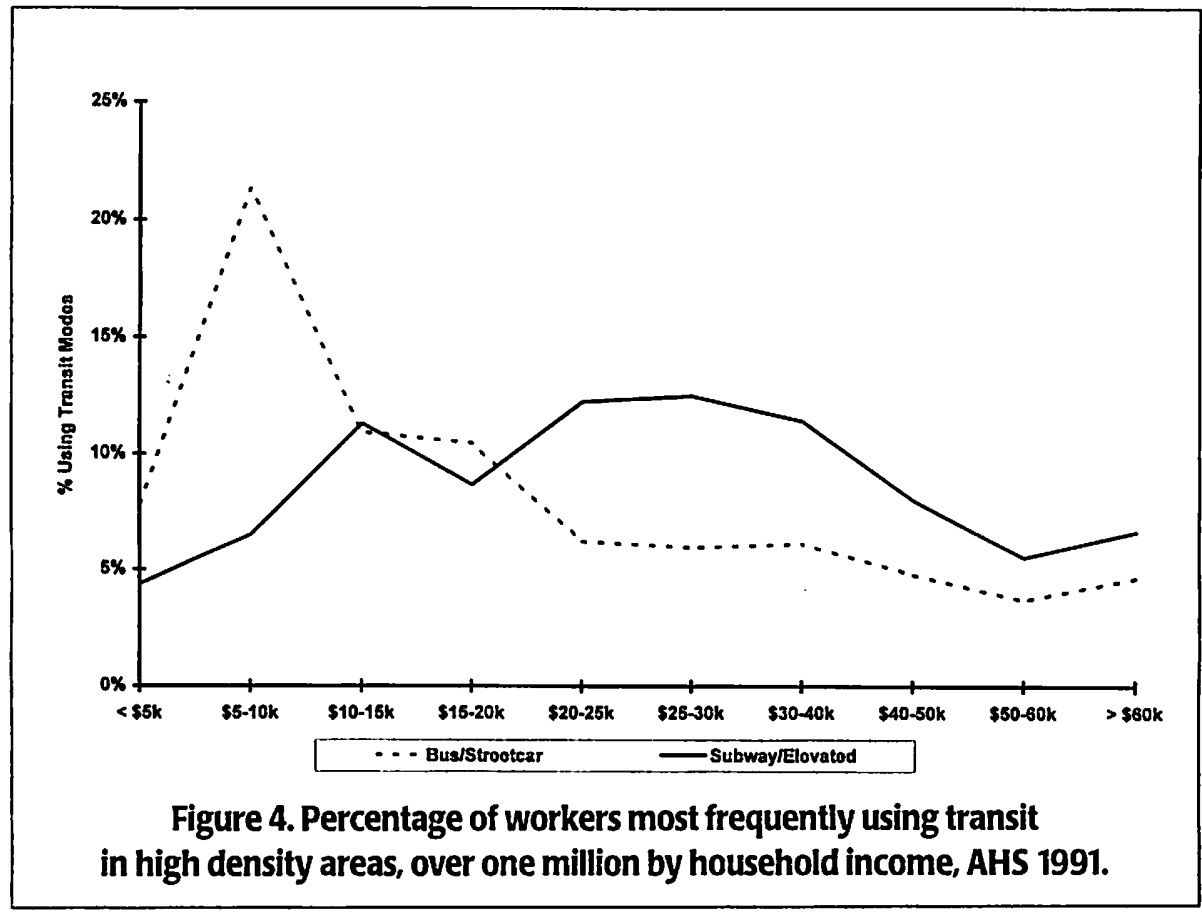


more than those making $\$ 25-30,000$. In fact, the tendency for bus use to rise with increasing income after $\$ 40,000$ is found in 10 of the 14 service environments. In short, neither rail or bus use in very large, dense cities fully explains why high income people are seen to use transit more in aggregate figures.

A comparable analysis of transit use patterns by race and ethnicity in the 14 service environments also does not support the hypothesis that higher transit use
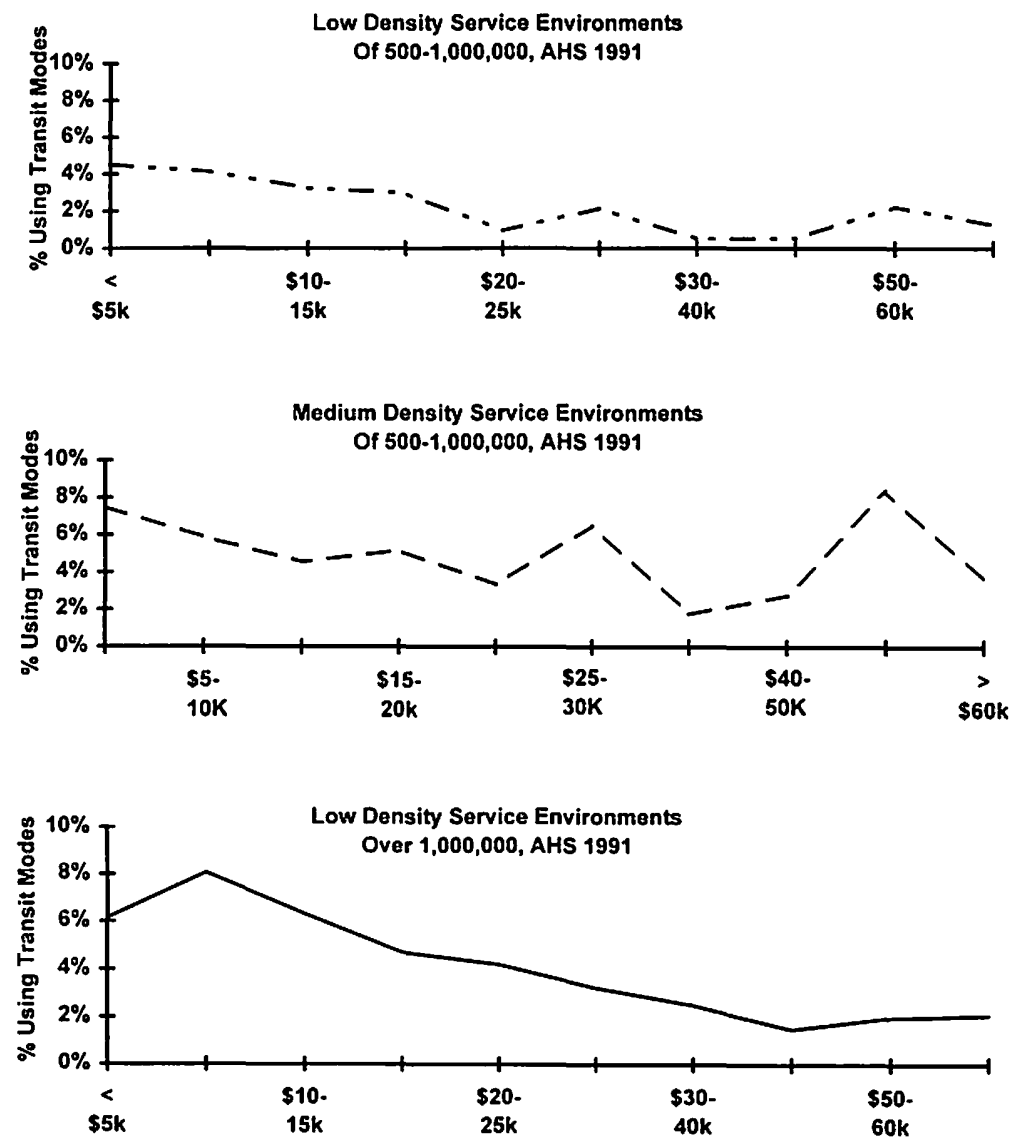

Figure 5. Percentage of bus use by income in three service environments. 
among blacks and Hispanics in the aggregate national figures results in a greater number of those groups live in large transit-oriented cities. Blacks were more likely to use transit than others of comparable income in 11 of the 14 service environments, including the smallest; Hispanics were more likely to use transit than other workers with comparable incomes in 9 of the 14 service environments. Of course, a metropolitan area is a very large unit; blacks and Hispanics may be concentrated in the (relatively) transit-rich areas of even the smallest and least dense community. However, as bad as housing segregation might be, it is unlikely that all people of color making relatively high incomes are living in older, denser, areas of town.

In short, while traditional explanations partially explain the income anomalies in the aggregate AHS data, they do not explain them all. Higher income workers and workers of color regardless of income are more likely to use transit, relatively independent of the characteristics of the metropolitan area.

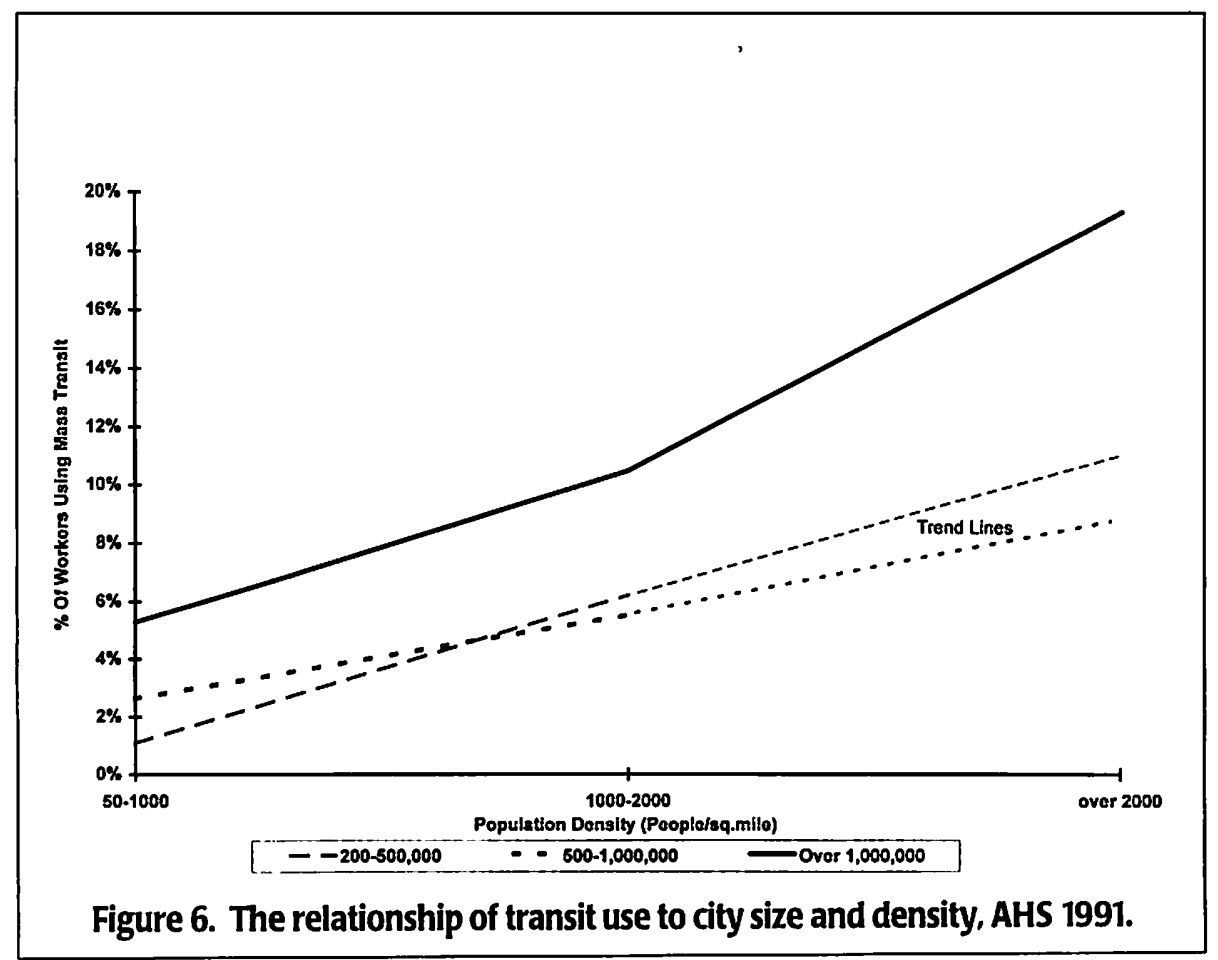




\section{The Role of Density}

A second surprising finding in the AHS data is the relationship between population density and transit ridership. While it is fairly well established that there is a positive relationship between the two, the role of density in enhancing transit ridership or affecting ridership among target groups is less clear. And, in fact, the AHS analyses suggests some perplexing interactions with community size.

Figure 6 shows that metropolitan area population itself explains more of the variation in transit use than does density. The figure first makes clear that, while both the size of the city and its density are directly proportional to transit use, the transit modal shift is generally substantial higher in larger cities-regardless of density. For example, at low densities (between 50-1,000 people/sq. mile) more than 5 percent of all workers in cities over one million used transit to commute to work, compared to only 1.4 percent of workers in cities below a half million.

While there are no cities under one million with high density (as defined here), a simple extrapolation of the trend line shows that even if smaller cities had higher density they would not have ridership equivalent to that found in larger cities. Note that no city with a population under one million-even with high density-would have even 10 percent of its workers using public transit, compared to almost 20 percent of workers in high density large cities.

It is, of course, possible that the relationship between density and ridership is not linear or that the way the density data have been categorized has "created" the trends seen in Figure 4. Moreover, the use of averages for a category that includes communities as disparate as New York and Chicago, on one hand, and Los Angeles and Houston, on the other, may obscure the "real" patterns. However, these findings should give us pause.

It may well be that people do not need to live at high average density to have access to the concentrated employment clusters that make transit more usable; perhaps bigger cities, like Los Angeles and Houston, offer sufficient suburban as well as CBD complexes to make transit more feasible for the work trip. Many large low density cities have both a) more people employed outside the traditional core than in it, and b) several suburban employment complexes, each with more workers than the traditional core. 
It may also be that larger cities simply offer more transit service, even in lower density areas. We know that people are more likely to use public transit if they live close to existing routes. For example, data from the 1990 NPTS show that, while transit use for all trips among the entire population is roughly 2 percent, it rises to 3.1 percent in areas where transit is generally available, and to 4.1 percent where transit is within one-quarter mile of the household. ${ }^{7}$ This suggests that there may be markets for transit in even some low density areas in larger cities.

\section{Summary}

The initial analyses of 1991 AHS transit data suggest that certain groupssuch as blacks and Hispanics-may be more likely to use transit than their incomes or residential locations alone would predict. The analyses also suggest that there may be an unexplained propensity to use transit among those with very high incomes. And, finally, the data hint at a complicated relationship between density and population size, with the size of a metropolitan area having more impact on transit use than density.

These findings could be, in part, a result of the way that the AHS sampled housing types, or the way the data were organized, although preliminary analyses of U.S. Census data suggest the same patterns. ${ }^{8}$ The findings are important enough, however, that these issues should be addressed in other national data sets ${ }^{9}$ and in local data sets which allow for more geographic disaggregation. In the initial analyses, the AHS patterns have messages for transit operators concerned with increasing or maintaining ridership.

Transit operators cannot assume captive ridership among many groups of traditional users; many low income workers do not use transit. At the same time, transit operators should not assume that there are no opportunities to attract high income users and moderate income minorities. Finally, the density analysis suggests that large but fairly low density communities might be able to create new or expand existing transit markets.

If these assumptions are true, and transit operators are seeking to both increase ridership from among current markets and increase ridership among those not generally using transit, they must focus more clearly on the needs of each 
group. Transit operators should begin to assess the kinds of services and options that would better meet the needs of people already more likely to use transit even if they do not fit traditional profiles (higher income riders, particularly those of color) and people who do fit traditional profiles but are not currently transit users (low income women, for example).

Transit operators cannot assume that ridership increases among either group can come from simply expanding current services or responding as they have historically. Rather, operators must focus on those options and services-from route restructuring to reverse commute routes-that match the real needs of the groups they are targeting Some of these groups may be served by the additional of traditional fixed route services while others would be better served by less traditional options-from vanpooling to general public dial-a-ride.

Above all, transit operators should be guided not by outdated understandings of why people use transit but by the experiences of communities that have specifically targeted these groups (and others) with a variety of transit servicesand succeeded in increasing transit ridership. Individual properties and the transit industry as a whole must both experiment with new approaches to marketing and service delivery to selected groups, and carefully monitor and disseminate the results.

\section{Acknowledgments}

Kelly Clifton was responsible for organizing the AHS data so transit use on the home to work trip for all workers could be evaluated and for organizing those data by community size and density; she was assisted by Paul Bechtel. Graphics were done by Jeff Walsh and Angela Mazzi.

\section{Notes}

1 Alan E. Pisarski, Travel Behavior Issues in the 90's, U. S. Department of Transportation, Federal Highway Administration, July 1922: 19.

2 U.S. Department of Transportation, Federal Highway Administration, Journey-ToWork Trends in the United States and Its Major Metropolitan Areas, 1960-90, Publication No. FHWA-PL-94-012, November 1993: 2-2.

3 U.S. Department of Transportation, Journey-to-Work Trends: 2-2. 
4 Patricia S. Hu and Jennifer Young, Summary of Travel Trends; 1990 Nationwide Personal Transportation Survey, U.S. Federal Highway Administration, Office of Highway Information Management, March 1992: 22.

$s$ Given the small number of transit trips-relative to the number of private vehicle trips-even a 20 percent undercount would not equal more than a very small percentage difference in the public modal split for the work trip.

6 Patricia S. Hu and Jennifer Young, 1990 NPTS Databook, Vol. I, U.S. Federal Highway Administration, Office of Highway Information Management, November 1993: 1-5.

7 U. S. Department of Transportation, Travel Behavior Issues in the 90 's: 22.

8 The Drachman Institute with G. J. Fielding, Transit Markets of the Future- The Challenge of Change, TCRP H-4B, Transit Cooperative Research Program, November 1995.

9 See The Drachman Institute with G. J. Fielding for a comparable assessment of these factors in the 1990 NPTS and the 19905 percent PUMS Census data.

\section{References}

Black, A. 1995. Urban Mass Transportation Planning. New York: McGraw Hill (esp. Chapters 5 and 12).

Fielding, G. J. 1995. Transit in American Cities. In S. Hanson, ed., Geography of Urban Transport, 2nd Edition. New York: Guileford Press.

Levinson, H. S. 1992. System and Service Planning. In G. E. Gray and L. Hoel, eds., Public Transportation, 2nd Edition. New York: Prentice Hall.

Rossetti, M., and B. Ebersole. 1993. Journey to Work Trends in the United States and Its Major Metropolitan Areas, 1960-1990. FHWA-PL-94-012, HPM-40/12-93, U.S. Department of Transportation, Federal Highway Administration.

\section{About the Authors}

SandRa Rosenbloom is the Director of the Roy P. Drachman Institute of the University of Arizona and a Professor of Planning in the University's Interdisciplinary Planning Program. Kelly Clifton is an Eisenhower Fellow working on her Ph.D. in Planning at the University of Texas at Austin. 